\title{
Double-blind, placebo-controlled study to evaluate the efficacy of fish oil and low-dose UVB in the treatment of psoriasis
}

\author{
A.K.GUPTA, C.N.ELLIS, D.C.TELLNER, T.F.ANDERSON AND \\ J.J.VOORHEES \\ Dermatopharmacology and Photobiology Units, Department of Dermatology, University of Michigan Medical \\ Center, Ann Arbor, and the Veterans Administration Medical Center, Ann Arbor, Michigan, U.S.A
}

Accepted for publication 9 December 1988

\section{SUMMARY}

Since eicosanoids have been implicated in the pathogenesis of psoriasis, less potent eicosanoid mediators derived from fish oil might improve psoriasis. Using a double-blind, randomized, parallel design, I8 patients with stable, plaque psoriasis received capsules of either fish oil or identical-appearing placebo olive oil for Is weeks, with concomitant sub-erythemal UVB in weeks 3 to II. At the conclusion of phototherapy, and 4 weeks later, patients in the fish oil group had a greater decrease in the total body surface area of psoriasis and more improvement compared to patients in the olive oil group. The improvement in the fish oil group was statistically significantly greater for all parameters compared to the change in the olive oil group. The apparent safety and general health-promoting features of fish oil could provide an ideal adjunctive therapy for psoriasis.

The oils of cold water fish are rich in long-chain polyunsaturated fatty acids, in particular those of the omega-3 series, e.g., eicosapentaenoic acid (EPA, 20 carbons and 5 double bonds, 20:5) and docosahexaenoic acid (DCHA, 22 carbon atoms and 6 double bonds, 22:6). Omega-3 indicates that the first double bond of the fatty acid, counting from the methyl end, occurs at the third bond. The polyunsaturated acids of fish oil have biological effects that differ from those in vegetable oil, such as linoleic acid, which belong to the omega- 6 series.

In involved plaques of psoriasis there is a marked increase in the levels of eicosanoids, e.g. arachidonic acid (AA), leukotriene $\mathrm{B}_{4}$ and 12 -hydroxyeicosatetraenoic acid (I2-HETE). ${ }^{1}$ In psoriasis, the 5-lipoxygenase pathway which converts AA to leukotrienes is enhanced and is associated with inflammation and cell proliferation. EPA can compete with AA as a substrate for

Correspondence: Dr C.N.Ellis, Department of Dermatology, University of Michigan Medical Center, Room I9I0, Taubman Center, 1500 East Medical Center Drive, Ann Arbor, Michigan 48109-0314, U.S.A.

Presented in part at the American Dermatological Association meeting in St. Moritz, Switzerland, 28 June-2 July I988. 
$\omega-6$ SERIES

ENZYME

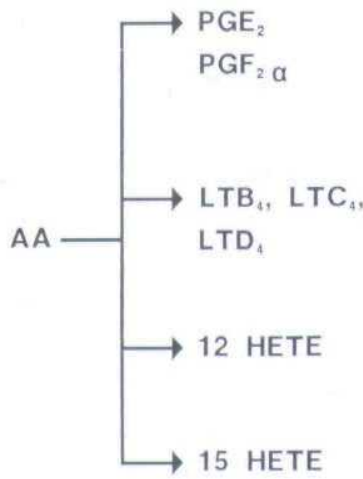

\begin{tabular}{|l|}
\hline CYCLO-OXYGENASE \\
5-LIPOXYGENASE \\
12-LIPOXYGENASE \\
15-LIPOXYGENASE
\end{tabular}

$\omega-3$ SERIES

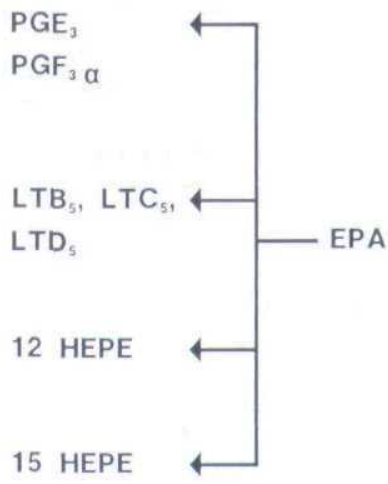

FIGURE I. Diagram showing the metabolism of arachidonic acid and eicosapentaenoic acid (PG, prostaglandin; LT, leukotriene; HETE, hydroxyeicosatetraenoic acid; EPA, eicosapentaenoic acid; DCHA, docosahexaenoic acid; HEPE, hydroxyeicosapentaenoic acid).

cyclo-oxygenase and lipoxygenase with subsequent production of less biologically active metabolites, ${ }^{2}$ such as leukotriene $\mathrm{B}_{5}$ (Fig. I). A diet rich in EPA would be expected to lead to an increased production of EPA metabolites of the omega- 3 series, and a decrease in the metabolites of AA of the omega- 6 series (Fig. I). A reduction in the inflammatory and proliferative components of psoriasis could occur, if dietary fish oil were taken regularly.

Administration of fish oils, containing large amounts of omega- 3 fatty acids, have been reported to be of benefit in the treatment of psoriasis ${ }^{3-8}$ and atopic dermatitis. ${ }^{9}$ We first demonstrated in an 8 week open trial that dietary fish oil supplementation with Max-EPA ${ }^{\mathrm{R}} 60-$ $75 \mathrm{gm}$ per day (I0.8-13.5 g of EPA) resulted in modest improvement of psoriasis. ${ }^{3}$ At similar doses of fish oil (9-12 g of EPA per day) for up to 3 months, other investigators noted clinical improvement in the majority of patients ${ }^{4,5}$ Bittiner et al. ${ }^{6,8}$ found fish oil (1.8 $\mathrm{g}$ EPA per day) to have some beneficial effect in psoriasis, whereas Bjorneboe et al. ${ }^{7}$ reported no such improvement using the same dose of fish oil.

The limited value of fish oil in all these studies suggests that it is not a monotherapy for psoriasis, but should be used as adjunctive therapy to more potent treatments. We decided to carry out a double-blind, randomized, placebo-controlled trial of parallel design to determine the efficacy of combined therapy with fish oil (3.6 gm EPA daily) and suberythemal doses of ultraviolet B (UVB) phototherapy twice weekly in mild to moderate psoriasis.

\section{METHODS}

Twenty adult subjects with stable psoriasis vulgaris $(10-50 \%$ total body surface area [TBSA] involvement) were chosen for this study. All patients had skin Type II or III and had no oral medications for psoriasis for the previous 4 weeks, and no topical therapy other than emollients for 2 weeks. During the course of the study, patients were permitted to use only the experimental therapy and emollients. Patients were asked to follow their normal diet during the 
course of therapy. Patients with acute guttate psoriasis, and pregnant or lactating women were excluded. Informed consent was obtained from each patient and the protocol was approved by the review board of the institution.

The subjects were randomly assigned to two groups. One group received to fish oil capsules twice daily (for a daily total of $3.6 \mathrm{~g}$ of EPA and $2.4 \mathrm{~g}$ of DCHA; Max-EPA ${ }^{\mathrm{R}}$; R.P. Scherer, Troy, Michigan, U.S.A). The other group was given identical appearing capsules containing olive oil (o mg EPA and DCHA; $76 \%$ oleic acid, $9 \%$ palmitic acid, $7 \%$ linoleic acid, $2 \%$ stearic acid; R.P.Scherer, Troy, Michigan, U.S.A). Nine subjects (six males and three females) with a mean age of $4 \mathrm{I}$ years (range 25-65) and mean TBSA involvement with psoriasis of $4 \mathrm{I} \pm 5 \%$ received fish oil capsules. Eleven subjects (eight males and three females), with mean age of $5 \mathrm{I}$ years (range 22-74) and TSBA $34 \pm 3 \%$ received placebo olive oil capsules. Patients were given fish oil (or placebo) for the first 3 weeks of the study (weeks o-3). At this point concomitant twice weekly therapy with suberythemal doses of UVB phototherapy for the next 8 weeks was initiated (weeks 3-II). For the last 4 weeks of the study (weeks I I-I5), only fish or olive oil was given.

For each patient, prior to UVB phototherapy, the minimal erythema dose (MED) required to produce faint erythema was determined. Ultraviolet B therapy was delivered to all patients, utilizing an Ultralight ${ }^{\mathrm{R}}$ phototherapy cabinet. Light therapy was initiated at $80 \%$ of the MED dose. In patients with skin type II, the UVB dosage in Joules was increased by a maximum of $10 \%$ just prior to the next phototherapy treatment if the patient had no UVB-induced erythema. In patients with skin type III, the corresponding increase was $20 \%$. No increase in the UVB dosage was carried out if erythema was present when the patient reported for a UVB treatment.

Patients were seen on a weekly basis for the first 3 weeks, and then every 2 weeks for the remainder of the study. Compliance was determined by history and by asking the patients to bring with them the medication containers. The severity of psoriasis was determined by measuring the TBSA and using a grading scale that assessed each of the parameters of scale, erythema and thickness $(0=$ absent, $\mathrm{I}=$ trace, $2=$ mild, $3=$ mild-moderate, $4=$ moderate, $5=$ moderate-severe, $6=$ severe).

Changes in scaling, erythema, thickness, TBSA and overall global response between the fish and olive oil groups were compared using the Students' two sample $t$-test. Differences between the two groups were assessed at pretherapy, the initiation of UVB therapy (week 3), the midpoint of UVB therapy (week 7), the conclusion of UVB therapy (week I I), and the end of the study (week $15 ; 4$ weeks off UVB therapy).

Means are reported with a confidence interval of \pm one standard error. All $P$ values are twosided.

\section{RESULTS}

Eighteen of 20 patients completed the 15 week study. One patient dropped out from each of the fish and the olive oil groups because of lack of response. Data is presented only for patients completing the study. None of the patients in either group reported any side-effects.

The scale, erythema, thickness and percentage TBSA during the study are shown in Table I. The sum of the scale, erythema and thickness scores $(0=$ no disease present to $18=$ severe disease) at pretherapy, weeks 3, 7, I I and I5 are presented in Fig. 2. In both the fish and olive oil groups, the pretherapy severity of psoriasis was of a comparable nature.

In the group receiving fish oil there were four patients with each of skin types II and III; in the 
TABLE I, Psoriasis severity parameters for fish and olive oil groups

\begin{tabular}{|c|c|c|c|c|c|c|c|c|c|}
\hline Parameter ${ }^{\star}$ & & $\begin{array}{c}\text { Week o } \\
\text { Pretherapy }\end{array}$ & $\begin{array}{l}\text { Week } 3 \\
\text { Oil alone }\end{array}$ & $\begin{array}{c}\text { Week } 7 \\
\text { Oil + UVB }\end{array}$ & $\begin{array}{c}\text { Week I I } \\
\text { Oil + UVB }\end{array}$ & $P+$ & $\begin{array}{l}\text { Week I5 } \\
\text { Oil alone }\end{array}$ & $\mathrm{P} \ddagger$ & $\begin{array}{l}\text { Per cent change } \\
\text { at end of study } \\
\text { (Week 15) } \\
\text { compared } \\
\text { to pretherapy }\end{array}$ \\
\hline Erythema & $\begin{array}{l}\text { FO } \\
\text { OO }\end{array}$ & $\begin{array}{l}3.5 \pm 0.3 \\
3.5 \pm 0.3\end{array}$ & $\begin{array}{l}3.0 \pm 0.3 \\
3.2 \pm 0.2\end{array}$ & $\begin{array}{l}2.2 \pm 0.3 \\
2.9 \pm 0.3\end{array}$ & $\begin{array}{l}2.2 \pm 0.3 \\
3.0 \pm 0.3\end{array}$ & NS & $\begin{array}{l}2.0 \pm 0.3 \\
3.5 \pm 0.5\end{array}$ & 0.02 & $\begin{array}{r}-43 \% \\
0 \%\end{array}$ \\
\hline Thickness & $\begin{array}{l}\text { FO } \\
\text { OO }\end{array}$ & $\begin{array}{l}3.3 \pm 0.6 \\
3.0 \pm 0.2\end{array}$ & $\begin{array}{l}3.2 \pm 0.4 \\
3.0 \pm 0.2\end{array}$ & $\begin{array}{l}2.3 \pm 0.4 \\
2.4 \pm 0.3\end{array}$ & $\begin{array}{l}2.0 \pm 0.4 \\
2.5 \pm 0.3\end{array}$ & NS & $\begin{array}{l}I \cdot 7 \pm 0 \cdot 4 \\
3 \cdot 2 \pm 0 \cdot 2\end{array}$ & 0.006 & $\begin{array}{r}-48 \% \\
7 \%\end{array}$ \\
\hline Scale & $\begin{array}{l}\text { FO } \\
\text { OO }\end{array}$ & $\begin{array}{l}3.1 \pm 0.4 \\
3 \cdot 3 \pm 0.2\end{array}$ & $\begin{array}{l}2.7 \pm 0.5 \\
3.1 \pm 0.4\end{array}$ & $\begin{array}{l}1 \cdot 2 \pm 0.7 \\
2 \cdot 7 \pm 0.3\end{array}$ & $\begin{array}{l}I .6 \pm 0.6 \\
2.4 \pm 0.3\end{array}$ & NS & $\begin{array}{l}2.0 \pm 0.7 \\
3.4 \pm 0.3\end{array}$ & 0.008 & $\begin{array}{r}-35 \% \\
+9 \%\end{array}$ \\
\hline TBSA $\%$ & $\begin{array}{l}\text { FO } \\
\text { OO }\end{array}$ & $\begin{array}{l}4 \mathrm{I} \pm 5 \\
34 \pm 3\end{array}$ & $\begin{array}{l}35 \pm 4 \\
36 \pm 3\end{array}$ & $\begin{array}{l}32 \pm 4 \\
36 \pm 3\end{array}$ & $\begin{array}{l}27 \pm 4 \\
34 \pm 5\end{array}$ & 0.05 & $\begin{array}{l}22 \pm 5 \\
45 \pm 2\end{array}$ & 0.0001 & $\begin{array}{l}-46 \% \\
+32 \%\end{array}$ \\
\hline
\end{tabular}

$\star$ Mean \pm SE, based on 6 point scale for erythema, thickness, scale; TBSA $=\%$ total body surface area involved with psoriasis.

$\mathrm{FO}=$ Fish Oil, $\mathrm{n}=8 ; \mathrm{OO}=$ Olive Oil, $\mathrm{n}=\mathrm{ro}$.

† By Student's two-sample $t$-test comparing the mean changes for each group from pretherapy to week II.

$\ddagger$ By Student's two-sample $t$-test comparing the mean changes for each group from pretherapy to week 15 .

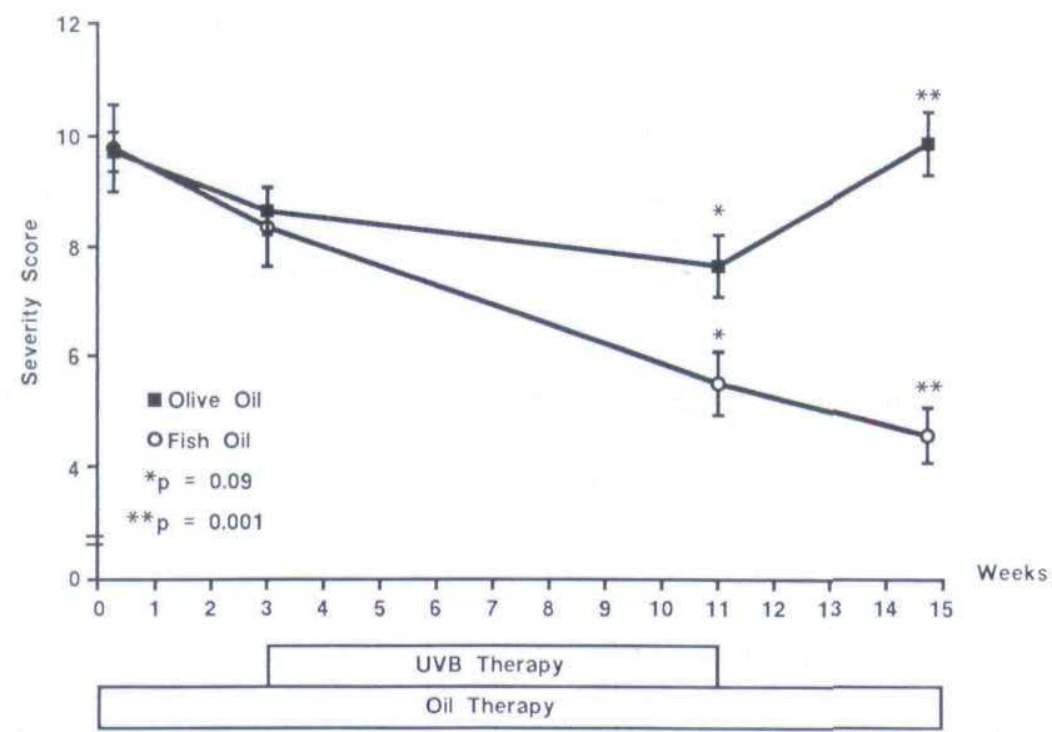

FIGURE 2. Mean sum of scores for scale, erythema, thickness at pretherapy, week 3, week I I and week I5 in the fish and olive oil groups. Severity score: $0=$ no disease and $18=$ severe disease; the bars indicate standard error. $P$ values were determined by Student's $t$-test comparing the mean sum of scores between the fish and olive oil groups. 
olive oil group, there were five patients with each of skin types II and III. Between weeks 3 and I I, the mean total amount of UVB received by the fish and olive oil groups was $I \cdot 6 \pm 0 \cdot 2$ Joules and $I \cdot 4 \pm 0.3$ Joules, respectively $(P=\mathrm{NS})$.

At the end of week 3 , the group receiving fish oil appeared to be improving more than the olive oil group (Table I). At week I I the group receiving fish oil had improved to a greater extent compared to pretherapy, than the patients receiving olive oil ( $P=0.05$ for TBSA) (Table I). At week 15 , the fish oil group had a $35 \%$ decrease in scale compared to pretherapy, while the group receiving olive oil had a 9\% increase; the comparable figures for erythema, thickness and TBSA were $-43 \%$ vs. $0 \%,-48 \%$ vs. $+7 \%$ and $-46 \%$ vs. $32 \%$ respectively. For both the fish and olive oil groups, the mean change in the scale, erythema, thickness and TBSA scores between end of therapy (week I 5) and pretherapy were calculated and the fish oil group had a statistically significantly better response for all parameters (Table I, Figure 2).

\section{DISCUSSION}

In our experience, ${ }^{3}$ fish oil, even at high doses, is not a practical monotherapy for psoriasis. This has also been reported in other studies in which psoriasis demonstrated only mild to moderate improvement ${ }^{4,5,6,8}$ or no improvement. ${ }^{7}$ In this study, there was no statistical advantage of fish oil over olive oil therapy in the first 3 weeks when oil therapy alone was used. After an additional 8 weeks of oil therapy combined with UVB treatment, we determined that the group receiving fish oil had a decrease in total body surface area, while the group receiving olive oil had no change in this parameter $(P=0.05)$ (Table I). After UV therapy had been stopped and oil therapy alone continued for 4 weeks, the fish oil group improved in all parameters studied compared to pretherapy while the group receiving olive oil had not changed or had worsened. The improvement in the fish oil group was statistically significantly greater for all parameters compared to the change in the olive oil group. These data show that improvement caused by fish oil and low dose UVB at week I I was maintained for a further 4 weeks by fish oil therapy but not by olive oil administration.

Twice weekly suberythemal UVB for 8 weeks is generally not sufficient as a monotherapy to clear psoriasis. Our UVB protocol was designed to be only minimally effective so as to maximize the relative effect of fish oil. With our study design, it is difficult to accurately determine the contribution of UVB relative to fish oil therapy toward the improvement in psoriasis. However, the degree of improvement noted in the group receiving low dose UVB and fish oil therapy was greater than would be expected following monotherapy with fish oil.

At the doses of fish oil (10.8-13.5 gm of EPA) used in our first study, ${ }^{3}$ no adverse side-effects were noted other than occasional 'fishy taste' on the breath upon eructation. In the present study, fish oil and placebo were given in identical-appearing tasteless, gelatinous capsules. In this dose and form, patients noted no 'fishy taste' on the breath upon eructation. Other studies, ${ }^{4-8}$ using similar or lower doses of fish oil for the treatment of psoriasis, have not reported side-effects. However, Saynor et al. ${ }^{10}$ found that patients who took $3.6 \mathrm{~g}$ of EPA daily for 2 years had significantly elevated bleeding times compared to those patients receiving $\mathrm{r} \cdot 8 \mathrm{~g}$ of EPA per day. The clinical significance of this is not clear, since in one study the effect on platelets in patients taking Io $\mathrm{g}$ of EPA per day for $\mathrm{I}$ month was less than occurs with one aspirin tablet $(325 \mathrm{mg})$ taken daily. ${ }^{11}$ It may be advisable not to prescribe fish oil to patients with bleeding disorders who are at risk for haemorrhagic complications.

Therapy with fish oil has other advantages besides its value in the treatment of the skin disease. ${ }^{12}$ In both normal and hyperlipidaemic subjects, dietary supplementation with fish oil 
rich in EPA and DCHA may result in reduction of serum triglycerides, cholesterol, and cholesterol-rich low density lipoproteins (LDL), ${ }^{13.14}$ and an elevation of serum high density cholesterol. ${ }^{15,16}$ Marsden $^{17.18}$ and Lowe et al. ${ }^{19}$ have shown that supplementation of diet with Max-EPA ${ }^{\mathrm{R}}$ reduces hyperlipidaemia induced by isotretinoin and etretinate. Thus the addition of fish oil to retinoid therapy for psoriasis may lead to a more desirable lipid profile, plus a modestly added therapeutic benefit. Some studies have reported that supplementation of the diet with fish oil may result in a reduction of platelet aggregation, blood viscosity and thrombotic tendency. ${ }^{20-22}$ Fish oil in the diet may also exert other cardioprotective effects. Kromhout $e t$ al. ${ }^{23}$ studied fish consumption in 852 middle aged men without coronary heart disease in the Netherlands. They were followed longitudinally for 20 years. Mortality from coronary heart disease was more than $50 \%$ lower among those who consumed at least $30 \mathrm{~g}$ of fish per day compared to those who did not eat fish. Omega-3 fatty acids have also been reported to reduce blood pressure. ${ }^{12}$

Since fish oil therapy is practical, has certain other potential advantages and a relative lack of side-effects, combination therapy of UVB and fish oil should be considered in the treatment of psoriasis. Fish oil administration may also provide a therapeutic advantage when combined with other therapies for psoriasis. Further studies need to be carried out to determine whether combined therapy with fish oil can lengthen the period of remission in patients with psoriasis.

\section{ACKNOWLEDGMENTS}

We would like to thank Ted A.Hamilton, M.S. (Biostatistics) for performing the statistical analysis and David McQuaid and Konrad Sadkowski for typing the manuscript. The study was partially supported by Babcock Dermatologic Endowment. We thank Dr Desmond Davies of R.P.Scherer Corporation (Troy, MI) for providing the fish and olive oil capsules. Max-EPA is a registered trademark of Seven Seas Health Care, Ltd., Hull, England.

\section{REFERENCES}

I Voorhees JJ. Leukotrienes and other lipoxygenase products in the pathogenesis and therapy of psoriasis and other dermatoses. Arch Dermatol 1983; 119: 54I-7.

2 Lokesh BR, German B, Kinsella JE. Differential effects of docosahexaenoic acid and eicosapentaenoic acid on suppression of lipoxygenase pathway in peritoneal macrophages. Biochimica et Biophysica Acta 1988; 958: 99-107.

3 Ziboh VA, Cohen KA, Ellis CN et al. Effects of dietary supplementation of fish oil on neutrophil and epidermal fatty acids. Arch Dermatol 1986; 122: 1277-82.

4 Allen BR, Maurice PDL, Goodfield MW et al. The effects on psoriasis of dietary supplementation with eicosapentaenoic acid. Br $\mathcal{F}$ Dermatol 1985; 133: 777 .

5 Maurice PDL, Allen BR, Barkley ASJ et al. The effects of dietary supplementation with fish oil in patients with psoriasis. $\mathrm{Br}$ f Dermatol 1987; 117: 599-606.

6 Bittiner SB, Tucker WFG, Bleehen SS. Fish oil in psoriasis-a double-blind randomized placebo-controlled trial. Br f Dermatol 1987; 117 : 25-6.

7 Bjorneboe A, Smith AK, Bjornboe G-EA et al. Effect of dietary supplementation with n-3 fatty acids on clinical manifestations of psoriasis. Br F Dermatol 1988; 118: 77-83.

8 Bittiner SB, Tucker WFG, Cartwright I et al. A double-blind, randomized, placebo-controlled trial of fish oil in psoriasis. Lancet 1988; i: $37^{8-80}$.

9 Bjorneboe A, Soyland E, Bjorneboe G-EA et al. Effect of dietary supplementation with eicosapentaenoic acid in the treatment of atopic dermatitis. Br F Dermatol 1987; 117: 463-9.

Io Saynor R, Verel D, Gillott T. The long-term effect of dietary supplementation with fish lipid concentrate on serum lipids, bleeding time, platelets and angina. Atherosclerosis $1984 ; 50: 3-10$.

II Knapp HR, Reilly AG, Alessandrini P et al. In vivo indexes of platelet and vascular function during fish-oil administration in patients with atherosclerosis. $N$ Eng $\mathcal{F}$ Med 1986; 314: 937-42. 
12 Schacky CV. Prophylaxis of atherosclerosis with marine omega-3 fatty acids. Ann Intern Med 1987; 107: 890-9.

13 Phillipson BE, Rothrock DW, Connor WE et al. Reduction of plasma lipids, lipoproteins, and apoproteins by dietary fish oils in patients with hypertriglyceridemia. New Eng f Med 1985; 312: 12 I0-6.

I4 Herold PM, Kinsella JE. Fish oil consumption and decreased risk of cardiovascular disease: a comparison of findings from animal and human feeding trials. Am f Clin Nutr 1986; 43: 566-98.

I5 Saynar R. Effects of $w_{3}$ fatty acids on serum lipids. Lancet 1984 ; ii: $692-3$.

I6 Sanders TAB, Roshanai F. The influence of different types of w3 polyunsaturated fatty acids on blood lipids and platelet function in healthy volunteers. Clinical Science $1983 ; 64: 91-9$.

I7 Marsden JR. Reduction of retinoid hyperlipidemia with Max-EPA. Br f Dermatol 1987; I16: 450.

I8 Marsden JR. Effect of dietary fish oil on hyperlipidemia due to isotretinoin and etretinate. Human Toxicol I987; 6: 219-222.

I9 Lowe NJ, Borok ME, Ashley JM et al. Fish oil consumption reduces hypertriglyceridemia in psoriatic patients receiving etretinate therapy. Arch Dermatol $1988 ;$ 124; 177.

20 Goodnight SH Jr, Harris WS, Connor WE. The effect of dietary w3 fatty acids on platelet composition and function in man: A prospective, controlled study. Blood 1981 ; 58: 880-5

2I Terano T, Hirai A, Hamazaki T et al. Effect of oral administration of highly purified eicosapentaenoic acid on platelet function, blood viscosity and red cell deformity in healthy human subjects. Atherosclerosis 1983; 46: $321-31$.

22 Siess W, Schrer B, Bohlig B et al. Platelet membrane fatty acids. Platelet aggregation and thromboxane formation during a mackerel diet. Lancet $1980 ;$ i: $44 \mathrm{I}-4$.

23 Kromhout D, Bosschieter EB, Coulander C de L. The inverse relation between fish consumption and 20 year old mortality from coronary heart diesease. New Eng f Med 1985; 312: 1205-9. 
This document is a scanned copy of a printed document. No warranty is given about the accuracy of the copy. Users should refer to the original published version of the material. 